https://www.journal-imab-bg.org

Original article

\title{
DETERMINATION OF PHENOLIC COMPOUNDS IN PRUNUS DOMESTICA FRUITS EXTRACT AND ITS PHARMACOLOGICAL ACTIVITY
}

\author{
Shahm B. Mohammed ${ }^{1}$, Taras V. Upyr ${ }^{2}$, Olga M. Shapoval ${ }^{3}$, Larysa V. Lenchyk ${ }^{1}$, \\ Kaloyan Georgiev 4 \\ 1) Department of Chemistry of Natural Compounds, National University of \\ Pharmacy, Kharkiv, Ukraine, \\ 2) Department of Pharmacognosy, National University of Pharmacy, Kharkiv, \\ Ukraine \\ 3) Department of Pharmacology and Prescription writing, Kharkiv National \\ Medical University Kharkiv, Ukraine \\ 4) Department of Pharmaceutical technologies, Faculty of pharmacy, Medical \\ University of Varna, Bulgaria.
}

\begin{abstract}
Qualitative composition and content of phenolic compounds in the liquid extract obtained from plum fruits have been studied. Five phenolic substances were found, as gallic acid, three hydroxycinnamic acids and rutin. The dominant substance was neochlorogenic acid $(2320 \pm 42 \mathrm{mg} / \mathrm{kg})$. Phenolic substances were identified in the extract and their amount determined by HPLC. Diuretic activity as diurnal spontaneous diuresis and forced diuresis, hypouricosemic and the membrane-stabilizing effects of plum liquid extract and its influence on the rheological properties of blood were studied.

Keywords: plum, fruits, extract, phenolic compounds, diuretic, hypouricosemic, membrane-stabilizing effect

\section{INTRODUCTION}

The plant Prunus domestica L., family Rosaceae is widely cultivated in Ukraine and Bulgaria. The recent studies showed that fruits have antioxidant, anticancer, antihyperglycemic, anti-hyperlipidemic, antihypertensive, antiosteoporosis, laxative and hepatoprotective activities $[1,2]$. Plant polyphenols are prospective for the study because they have a wide range of pharmacological activity and play a leading role in the regulation of oxidative balance in the human body [3]. Obtaining of extract from Prunus domestica L. fruits, investigation its polyphenolic composition and pharmacological effects can help further creation of new effective drugs or food supplement with low toxicity.

Therefore, the aim of our research was the determination of the phenolic compounds in plum fruits liquid extract and its toxicity, diuretic hypouricosemic, membrane-stabilizing effect and influence on the rheological properties of blood.
\end{abstract}

\section{MATERIALS AND METHODS}

The object of the study was an extract obtained from Prunus domestica fresh fruits "vengerka" variety harvested in September, in Kharkiv region in 2016.

$0,5 \mathrm{~kg}$ of fruits were splitted, stones were removed, and fruits were comminuted to puree. $400 \mathrm{~g}$ of puree was mixed with $800 \mathrm{ml}$ of water in the flask, and the mixture was centrifuged. Liquid part was decanted into flask, concentrated to $600 \mathrm{ml}$ and $1800 \mathrm{ml}$ of $96 \%$ ethyl alcohol were added and mixed. The precipitation was separated. Liquid part was concentrated to $400 \mathrm{ml}$, and alcohol was eliminated. The plum fruits liquid extract (PFLE) was divided into two equal parts and used for chemical analysis as well as for pharmacological research.

For preliminary identification of biologically active substances in PFLE paper chromatography (PC) and thin layer chromatography (TLC) were used. TLC study was carried out in the solvent systems such as formic acid anhydrous - water - butanol (16:19:65), glacial acetic acid - water-ethyl acetate (20:20:60), butanol - glacial acetic acid - water (4:1:2) and $15 \%$ acetic acid. Analysis was performed on the TLC plates with a layer of F254 Merck silica gel, $20 \times 10 \mathrm{~cm}$ on a glass substrate. For identification of hydroxycinnamic acids obtained chromatograms were treated by a solution of aminoethyl ester of diphenyl boric acid in methanol and then macrogol solution and after that, the plate was heated at a temperature of $100-105^{\circ} \mathrm{C}$ for $10 \mathrm{~min}$ and viewed in daylight $[4,5]$. For identification, phenolic compounds ammonia solution and azo coupling reagent were used. Presence of organic acids was confirmed by PC analysis in the solvent systems ethyl acetate-acetic acid-formic acid-water (100: 11: 11: 25); ethanol - chloroform - ammonia - water, (70: 40: 20: 2); ethyl acetate - formic acid - water, $(3: 1: 1)$ with standard samples of organic acids. Chromatograms were treated with a solution of bromophenol blue and methyl red and heated in a drying cabinet at a temperature of $105^{\circ} \mathrm{C}$. Organic acids appear as yellow spots on a blue background [6]. Composition and content of phenolic compounds in PFLE also were studied with Shimadzu HPLC-system, ser. 20, completed with diode array detector [7-9]. For analysis chromatographic column 250 $\times 4,6 \mathrm{~mm}$, filled sorbent grained 5 microns, "Phenomenex Luna C18" was used. The wavelength of detection of hydroxycinnamic acids was $330 \mathrm{~nm}$, and flavonoids $-370 \mathrm{~nm}$, the temperature of the thermostat was $35^{\circ} \mathrm{C}$; mobile phase flow rate 
- $1 \mathrm{ml} / \mathrm{min}$, the operating pressure of the eluent was 240-300 $\mathrm{kPa}$. Gradient regime of chromatography is given in table 1. Parameters of analysis were the scale of measurement - 1.0; scan time - 0.5 seconds; options metering spectrum - each peak of 190-600 nm. [5, 8]. Each peak detected in the PFLE was identified by comparing retention time and UV spectra given by diode array detector with the standards.

Table 1. Gradient regime of chromatography of PFLE

\begin{tabular}{|c|c|c|}
\hline $\begin{array}{c}\text { Chromatography } \\
\text { time }(\mathrm{min})\end{array}$ & $\begin{array}{c}\text { Mobile phaseA }(0.1 \% \text { trifluoroacetic } \\
\text { acidin water }), \%\end{array}$ & $\begin{array}{c}\text { Mobile phaseB }(0.1 \% \text { trifluoroacetic acid in } \\
\text { acetonitrile }), \%\end{array}$ \\
\hline $0-5$ & 95 & 5 \\
\hline $5-35$ & $95 \rightarrow 75$ & 25 \\
\hline $35-40$ & 75 & $25 \rightarrow 50$ \\
\hline $40-60$ & $50 \rightarrow 20$ & $50 \rightarrow 80$ \\
\hline $60-65$ & 20 & 80 \\
\hline $65-70$ & 95 & 5 \\
\hline $70-85$ & & 50 \\
\hline
\end{tabular}

The flavonoids, hydroxycinnamic acids were quantified by calibration with the standards. Volume of the entered sample was $5 \mathrm{ml}$ and analyzed in triplicate. The statistical processing of results was carried out with package Statistica 6.0. The error did not exceed $5 \%$.

The pharmacological research was performed in accordance with "The General Ethical Principles of Animal Experimentation" (Ukraine, 2001), which are consistent with the provisions of "The European Convention for the Protection of Vertebrate Animals Used for Experimental and Other Scientific Purposes" (Strasbourg, 1986) [10, 11].

The safety of PFLE was studied with an investigation of acute toxicity with white rats after single intragastric administration of PFLE for determination the $\mathrm{LD}_{50}$ dose in accordance with Ukraine guidelines [11]. The limiting measure in the determination of the $\mathrm{LD}_{50}$ was the maximum dose of fourth-grade toxicity (low-toxic substances) - $5000 \mathrm{mg} / \mathrm{kg}$ [11]. So, 24 white rats (male and female) were randomized into 2 groups: 1-st group of Intact Control (IC) -6 males and 6 females rats that used solvent (water), 2-nd group - 6 males and 6 females rats that used PFLE in dose $5000 \mathrm{mg} / \mathrm{kg}$. The animals were observed for 14 days.

A unified methodical scheme was used to determine the dynamics of diuresis, to study the effect of PFLE on the state of the urinary system and thereby to determine the presence of diuretic and hypouricosemic activity [12]. Diuretic activity was studied in terms of diurnal spontaneous diuresis and forced diuresis (with a liquid load in a volume of $3 \%$ of animal's body weight, which was done 1 hour after the use of PFLE) in rats. Spontaneous diuresis was studied at 1-st day of the study after a single dose and 20-day intragastric administration of PFLE in a dose of $5 \mathrm{ml} / \mathrm{kg}$. After 2-nd and 21-st days from the start of the experiment, immediately after the study of spontaneous diuresis, forced diuresis was studied after a 2-nd and 21-st intragastric administration of PFLE in a dose of $5 \mathrm{ml} / \mathrm{kg}$. In the same mode, the control group of rats received an equivalent amount of solvent (drinking water). In the study of spontaneous diuresis for the collection of urine, the rats were placed in metabolic cages for 24 hours and in the study of forced diuresis - for 3 hours [12]. At the end of the experiment, animals were subjected to euthanasia according to ethical requirements when working with laboratory animals and collected blood for serum production. The concentration of creatinine and uric acid was determined with the biochemical set of reagents ("Filisit", Ukraine) in urine and serum. Excretion of creatinine and uric acid was calculated by the formula [13]. According to the method presented in [14], the velocity of glomerular filtration and relative reabsorption of fluid were calculated.

The influence of PFLE on the rheological properties of blood was investigated because the removal of excess fluid from the body can cause increasing blood density and the risk of thrombosis. After randomization, the animals had intragastric administration of water (IC group) and PFLE in a dose of $5 \mathrm{ml} / \mathrm{kg}$ (PELE group) during 3 weeks. At the end of the experiment, after the incision of the tip of the tail of the rats, the time of coagulation of the first drop of blood was determined [15]. It was determined the ability of PFLE to reduce the time of blood coagulation in rats compared to IC and expressed in percentage (\%).

The study of the influence of PFLE on the state of cell membranes was performed under conditions of spontaneous hemolysis of erythrocytes of rats according to Jager F.C. [15]. After randomization, 2 groups of animals received intragastrically PFLE in a dose of $5 \mathrm{ml} / \mathrm{kg}$ (PELE group) and equivalent amount of solvent (water) (IC group) for 3 weeks. Further, the determination of the degree of hemolysis of erythrocytes was carried out by the method [15]. The membrane-stabilizing effect of PFLE was determined by the ability to prevent damage of the erythrocyte membrane and was evaluated by changing the number of rat's hemolysed erythrocytes in compared to the IC group and expressed as \%.

\section{RESULTS}

After our preliminary study of PFLE by TLC and PC, it was confirmed the presence of organic acids (malic, citric) 
hydroxycinnamic acids and flavonoids (anthocyanidins). As a result of the study of PFLE by HPLC 5 phenolic compounds were determined. Graphical results can be seen in figure 1.
The amount of determined compounds was given in $\mathrm{mg} / \mathrm{kg}$ (Table 2).

Fig. 1. The graphical result of HPLC investigation of phenolic compounds of PFLE

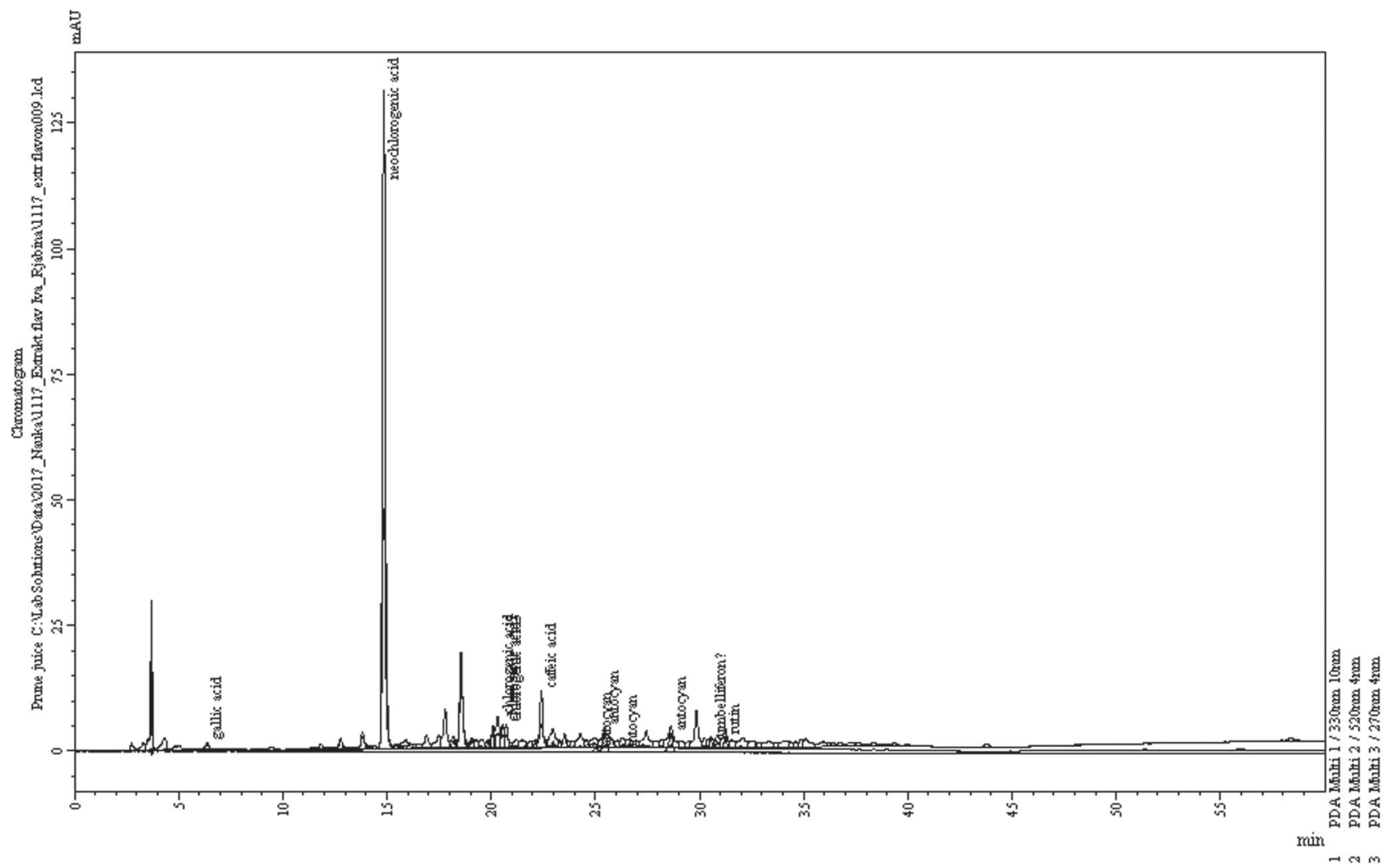

Table 2. The phenolic composition of PFLE $(n=3)$

\begin{tabular}{|l|c|c|}
\hline Compound & Retention time, min & Content, $\mathrm{mg} / \mathrm{kg}$ \\
\hline Gallic acid & 5.32 & $56 \pm 5$ \\
\hline Neochlorogenicacid & 14.81 & $2320 \pm 42$ \\
\hline Chlorogenicacid & 20.18 & $78 \pm 8$ \\
\hline Caffeic acid & 21.96 & $373 \pm 12$ \\
\hline Rutin & 31.02 & $31 \pm 1$ \\
\hline
\end{tabular}

The predominant component was neochlorogenic acid. The total amount of determined compounds was 2858 $\mathrm{mg} / \mathrm{kg}$. Among the biologically active substances of PFLE were found organic acids, hydroxycinnamic acids, which are characterized by an antioxidant, anti-inflammatory, membrane-stabilizing, cytoprotective and organo-protective effects that can restore the density of biomembranes and func- tional activity of cells, tissues, organs, systems and the organism as a whole. Taking into account the above, it was expedient to study the influence of PFLE on the functional state of cell membranes in the conditions of erythrocyte hemolysis in rats and the ability to exhibit membrane-stabilizing activity. The results of the pharmacological study can be seen in tables 3-6.

Table 3. Indicators of kidney's function of rats with spontaneous diurnal diuresis

\begin{tabular}{|l|l|l|l|}
\hline Indicators & Term & Intact control (IC) & PFLE,5 ml/kg \\
\hline \multirow{2}{*}{ Urine volume (D), $\mathrm{ml}$} & Initial data & $4,52 \pm 0,21$ & $6,65 \pm 0,74^{*}$ \\
\cline { 2 - 4 } & 3 weeks & $3,52 \pm 0,51$ & $3,82 \pm 0,48$ \\
\hline Diurnal diuresis (V), ml/100 g & Initial data & $2,20 \pm 0,12$ & $3,16 \pm 0,39^{*}$ \\
\cline { 2 - 4 } & 3 weeks & $1,62 \pm 0,25$ & $1,81 \pm 0,11$ \\
\hline
\end{tabular}




\begin{tabular}{|l|l|l|l|}
\hline \multirow{2}{*}{ Amount of creatinine in urine, mg } & Initial data & $2,47 \pm 0,39$ & $5,39 \pm 0,44^{*}$ \\
\cline { 2 - 4 } & 3 weeks & $2,77 \pm 0,33$ & $10,08 \pm 1,77^{*}$ \\
\hline \multirow{2}{*}{ Creatinine in urine, mmol/l } & Initial data & $5,19 \pm 0,74$ & $6,58 \pm 0,66$ \\
\cline { 2 - 4 } & 3 weeks & $7,17 \pm 0,65$ & $22,98 \pm 3,32^{*} / *$ \\
\hline \multirow{2}{*}{ Creatinine excretion, mmol/100 g } & Initial data & $2,64 \pm 0,45$ & $3,35 \pm 0,26^{*}$ \\
\cline { 2 - 4 } & 3 weeks & $4,99 \pm 0,78$ & $16,02 \pm 2,12^{* * *}$ \\
\hline \multirow{2}{*}{ Uric acid in urine, mmol/l } & Initial data & $2,37 \pm 0,16$ & $2,57 \pm 0,15$ \\
\cline { 2 - 4 } & 3 weeks & $1,51 \pm 0,24$ & $1,40 \pm 0,11$ \\
\hline \multirow{2}{*}{ Excretion of uric acid, mmol/100 g } & Initial data & $1,20 \pm 0,13$ & $1,32 \pm 0,11$ \\
\cline { 2 - 4 } & 3 weeks & $1,06 \pm 0,25$ & $1,02 \pm 0,21$ \\
\hline
\end{tabular}

Note: * - rejection rate is likely related to the group of data of intact controls, $\mathrm{p}<0.05 ; * *$ - rejection rate significantly on the initial data, $\mathrm{p}<0.05$.

Table 4. Indicators of kidney function of rats with diuresis with water loading

\begin{tabular}{|c|c|c|c|}
\hline Indicators & Term & Intact control (IC) & PFLE, $5 \mathrm{ml} / \mathrm{kg}$ \\
\hline \multirow[t]{2}{*}{ Urine volume (D), $\mathrm{ml}$} & Initial data & $3,58 \pm 0,41$ & $3,12 \pm 0,38$ \\
\hline & 3 weeks & $3,20 \pm 0,54$ & $1,98 \pm 0,36 * / * *$ \\
\hline \multirow[t]{2}{*}{ Diurnal diuresis $(\mathrm{V}), \mathrm{ml} / 100 \mathrm{~g} \times \mathrm{h}$} & Initial data & $0,58 \pm 0,06$ & $0,48 \pm 0,07 *$ \\
\hline & 3 weeks & $0,49 \pm 0,08$ & $0,22 \pm 0,04 * / * *$ \\
\hline \multirow[t]{2}{*}{ Creatinine in urine, $\mathrm{mmol} / \mathrm{l}$} & Initial data & $2,79 \pm 0,34$ & $5,56 \pm 0,43^{*}$ \\
\hline & 3 weeks & $3,99 \pm 0,57$ & $2,80 \pm 0,15 * / * *$ \\
\hline \multirow[t]{2}{*}{ Creatinine excretion, $\mathrm{mmol} / 100 \mathrm{~g}$} & Initial data & $1,77 \pm 0,35$ & $3,53 \pm 0,23 *$ \\
\hline & 3 weeks & $3,41 \pm 0,94$ & $2,39 \pm 0,62$ \\
\hline \multirow[t]{2}{*}{ Velocity of glomerular filtration, $\mathrm{ml} / 100 \mathrm{~g} \times \mathrm{h}$} & Initial data & $13,91 \pm 0,66$ & $22,24 \pm 1,46^{*}$ \\
\hline & 3 weeks & $13,22 \pm 1,86$ & $4,74 \pm 1,14 * / * *$ \\
\hline \multirow[t]{2}{*}{ Serum uric acid, mmol / 1} & Initial data & $62,00 \pm 3,58$ & $64,14 \pm 4,28$ \\
\hline & 3 weeks & $88,51 \pm 11,00$ & $97,20 \pm 4,31$ \\
\hline \multirow[t]{2}{*}{ Uric acid in urine, $\mathrm{mmol} / \mathrm{l}$} & Initial data & $0,73 \pm 0,08$ & $0,82 \pm 0,14$ \\
\hline & 3 weeks & $0,55 \pm 0,05$ & $0,39 \pm 0,04 *$ \\
\hline \multirow[t]{2}{*}{ Excretion of uric acid, mmol $/ 100 \mathrm{~g}$} & Initial data & $0,44 \pm 0,06$ & $0,49 \pm 0,05$ \\
\hline & 3 weeks & $0,47 \pm 0,12$ & $0,76 \pm 0,16^{*}$ \\
\hline
\end{tabular}

Note: * - rejection rate is likely related to the group of data of intact controls, $\mathrm{p}<0.05 ; * *$ - rejection rate significantly on the initial data, $\mathrm{p}<0.05$.

Table 5. Three-week influence of PFLE on rheological properties of rat blood

\begin{tabular}{|l|c|c|}
\hline Indicators & Intact control (IC) & PFLE, $5 \mathrm{ml} / \mathrm{kg}$ \\
\hline Clotting time, sec & $69,67 \pm 8,04$ & $79,33 \pm 7,23$ \\
\hline Hemolytic action, $\%$ & - & 14,0 \\
\hline
\end{tabular}

Note: * - rejection rate is likely related to the group of data of intact controls, $\mathrm{p}<0.05$

Table 6. Three-week influence of PFLE on the state of rat cell membranes in the model of erythrocytes spontaneous hemolysis by Jager F.C.

\begin{tabular}{|l|c|c|}
\hline Indicators & Intact control (IC) & PFLE,5 m1/kg \\
\hline Degree of erythrocytes hemolysis, $\%$ & $10,36 \pm 0,74$ & $6,93 \pm 0,72 *$ \\
\hline Membrane-stabilizing activity, $\%$ & - & 33 \\
\hline
\end{tabular}

Note: * - rejection rate is likely related to the group of data of intact controls, $\mathrm{p}<0.05$ 


\section{DISCUSSION}

The results of the research allowed determining the total amount of phenolic compounds, studied by HPLC, in the plum fruits extract, which comprised $2858 \mathrm{mg} / \mathrm{kg}$, among which the content of hydroxycinnamic acids was $2771 \mathrm{mg} / \mathrm{kg}$, while flavonoids were found in minor quantities.

The correlation of hydroxycinnamic acids to flavonoids in the fruits somewhat differed from the result previously obtained by us while studying the chemical composition of plum leaves [5]. The ratio of hydroxycinnamic acids to flavonoids in the leaves was $2: 1[5,3]$. The determined antioxidant activity of the plum leaves extract was probably due to the high content of hydroxycinnamic acids along with flavonoids [5]. This hypothesis is based on the results of the in vitro and in vivo research that have demonstrated the chlorogenic acid to possess the antioxidant activity; it protected granulocytes from the oxidative stress [16].

The extract we obtained is non-toxic since at a dose of $5000 \mathrm{mg} / \mathrm{kg}$ the death of animals was not registered, thus, PFLE at intragastic administration can be ascribed to the $\mathrm{V}$ toxicity class (almost non-toxic substances) [15].

At the background of spontaneous diuresis PFLE did not change the diuresis volume and diurnal diuresis after intragastric administration at a dose of $5 \mathrm{ml} / \mathrm{kg}$ during 21 day (3 weeks) compared to IC (Table 3), though at the beginning of the experiment the increase of urine volume in animals by $47,1 \%$ against the IC group $(\mathrm{p}<0,05)$ and diurnal diuresis by $43,6 \%(\mathrm{p}<0,05)$ was observed (Table 3$)$. PFLE might only eliminate the excess water without disturbing the body water balance. However, under the conditions of forced diuresis PFLE was found to show no influence on the diuretic activity after one-time application but suppressed it after prolonged administration (Table 4). After 3 weeks of administration PFLE caused significant decrease of the urine volume by $37 \%$ ( $p$ $<0,05)$ and diurnal diuresis by $55 \%(\mathrm{p}<0,05)$. This result is confirmed by the glomerular filtration speed reduction by $64 \%$ compared to the initial data and the IC data (Table 4). Hence, under the condition of forced diuresis on the long-term PFLE administration the stress in the function of kidneys is observed and the filtration ability of kidneys is changed, the reabsorption is suppressed, which is extremely important in the gout treatment.

Besides that, the content of creatinin and uric acid in serum and urine, which are the markers of the nitrogen balance and the purine metabolism respectively, was studied in our experiment (Table 3-4). Concerning spontaneous diure- sis, after one-time and 3-weeks administration PFLE has shown that the increase of creatinin in urine was 1.1 times ( $p$ $<0,05)$ and 3.2 times $(p<0,05)$ higher compared to IC (Table 3 ). Under the condition of forced diuresis a single PFLE dose increased the creatinin level in urine and stimulated the increase of creatinin excretion values twice $(p<0,05)$ compared to IC (Table 4). After 3 weeks of PFLE administration the creatinin excretion and the speed of glomerular filtration were respectively 1.43 times $(p<0,05)$ and 2.8 times $(p<0,05)$ lower compared to IC. In 3 weeks PFLE 1.4 times $(p<0,05)$ decreases the uric acid level in urine, and 1.6 times $(\mathrm{p}<0,05)$ stimulates the increase of uric acid excretion values compared to IC (Table 4). These results have shown a strong capacity of PFLE to eliminate creatinin and uric acid (pathogenic products of nitrogen and purine metabolism respectively) from the body, the presence of hypouricosemic activity, and allowed recommending PFLE in gout treatment.

The research on the impact of PFLE on the blood rheological properties has shown that PFLE caused the extension of blood coagulation time by $14 \%(p<0,05)$ compared to IC (Table 5). This is indicative of the possible antiaggregant and anticoagulant properties of PFLE.

The ability of PFLE to prevent damage of erythrocytes cell membranes and significantly $(1.5$ times, $(\mathrm{p}<0,05))$ decrease the level of erythrocyte hemolysis compared to IC (Table 6) was detected. The PFLE membrane-stabilizing activity comprised 33\% ( $\mathrm{p}<0,05)$ (Table 6), which allows expecting its cytoprotective, antioxidant and metabolic properties, as well as positive impact on the body cells functioning (e.g., blood cells, kidney cells, liver cells, etc.). These properties may be explained by the fact that PFLE contains phenolic compounds, such as hydroxycinnamic acids, with proven antioxidant and cytoprotective activity [16]. Thus, the results of pharmacological research show the diuretic, hypouricosemic, membrane-stabilizing activity of PFLE and its positive impact on the blood rheological properties, which allows recommending PFLE for further research for the creation of a new agent for gout treatment.

\section{CONCLUSIONS}

The study of the chemical composition of PFLE was carried out using PC, TLC and HPLC methods. The prospects of creating a new agent with hypouricosemic, membrane-stabilizing effects were proven. The results obtained will be further used in the PFLE standardization and further pharmacological research on its activity.

\section{REFERENCES:}

1. Pharmaceutical encyclopedia. 2nd ed.: Chairman Ed. Council Chernykh V.P. Kiev: "MORION"; 2016: 1952. [in Ukrainian].

2. Qaiser J, Naveed A.The pharmacological activities of prunes: The dried Plums. J Med Plant Res. 2011; 5(9): 1508-1511.

3. Zagayko A, Senuyk I, Lenchyk
L, Galimullin R. Study of antioxidant activity of the extract from plum ordinary leaves. Ukrainian biopharmaceutical journal. 2014; 1(30): 25-28. [in Ukrainian].

4. Kovaleva AM, Abdulkafarova ER. Phenolic compounds from Potentilla anserina. Chem Nat Compd. 2011 Jul;47(3):446-7. [Crossref]
5. Lenchyk LV. Determination of phenolic compounds in Prunus domestica leaves extract. Scripta Scientifica Pharmaceutica. 2015; 2(2):35-39. [Crossref]

6. Upyr TV. The study of the organic acids in dry extract of Ledum palustre shoots. Ukrainian Biopharmaceutical J. 2016; 6(47):71-74. 
7. Chen LJ, Hrazdina G. Structural aspects of anthocyanin-flavonoid complex formation and its role in plant color. Phytochemistry. 1981; 20(2): 297-303. [Crossref]

8. McMurrough I, Hennigan GP, Loughrey MJ. Quantitative analysis of hop flavonols using high-performance liquid chromatography. J Agric Food Chem. 1982 Nov;30(6):1102-6. [Crossref]

9. Vovk G, Koshovyi O, Komissarenko A. Study of dry extract phenolic compounds of sage leaves, obtained by complex processing after tincture production. Collection of scientific works of staff members of NMAPE. 2014; 4: 237 - 40.

10. European convention for the protection of vertebrate animals used for experimental and other scientific purposes // Council of European. Strasbourg, 1986. No. 123. 51 ð.

11. Experimental study of the toxic effects of potential medicinal products / Preclinical studies of medicinal products: [method. rivers] / VM. Kovalenko, OV. Stefanov, YuM. Maksimov, IM Trachtenberg. K.: Avicenna, 2001; 7497. [in Ukrainian].

12. Shumskaya NI, Karamzina N.N. To the evaluation of the functional state of the kidneys in rats during industrial poisoning / Toxicology of new industrial chemicals. L.: Medicine, 1966. (8): 14-27. [in Russian]

13. Functional biochemistry / $\mathrm{AL}$ Zagayko, LM Voronina, MV Voloshen- ko et al. Kh. NUPh, 2010. 220 p. Ukrainian.

14. Gozhenko AI, Kuksan NI, Pogorila IV Functional state of the kidneys in a chronic blockade of synthesis of nitric oxide in rats // Medical Chemistry. 2002; 4. (4): 65-8. [in Ukrainian]

15. Kamyshnikov VS Reference book on clinical and biochemical laboratory diagnostics. - Minsk "Belarus", 2000: 268-281. [in Russian]

16. Bouayed J, Rammal H, Dicko A, Younos C, Soulimani R. Chlorogenic acid, a polyphenol from Prunus domestica (Mirabelle), with coupled anxiolytic and antioxidant effects. $J$ Neurol Sci. 2007 Nov 15;262(1-2):7784. [ubMed] [Crossref]

Please cite this article as: Mohammed SB, Upyr TV, Olga M. Shapoval OM, Lenchyk LV, Georgiev K. Determination of phenolic compounds in Prunus domestica fruits extract and its pharmacological activity. J of IMAB. 2019 Apr-Jun;25(2):25892594. DOI: https://doi.org/10.5272/jimab.2019252.2589

Received: 29/11/2018; Published online: 27/06/2019

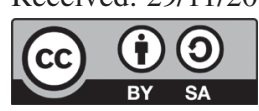

Address for correspondence:

Larysa Lenchyk

Chemistry of Natural Compounds Department, National University of Pharmacy.

53, Pushkinska str., Kharkiv 61002, Ukraine.

E-mail: larysa.lenchyk@gmail.com 